\title{
Assigning hatchlings to eggs: Is relative mass assignment an accurate method?
}

\author{
J. Dylan Maddox ${ }^{1,2^{*}}$ (1)
}

\begin{abstract}
Background: Accurately assigning hatchlings to the eggs from which they hatched is a prerequisite to understanding how the composition and environment of eggs affect the growth and survival of nestlings. Correctly assigning hatchlings to their eggs can be a challenging endeavor, however, because multiple eggs within the same clutch can hatch at essentially the same time. Egg and hatchling mass are highly correlated in most bird species, and thus assigning eggs to hatchlings using their relative mass (e.g., matching the heaviest hatchling to the heaviest candidate egg) could prove extremely useful.
\end{abstract}

Methods: To assess its potential utility, I applied relative mass assignment (RMA) retrospectively to a dataset of 133 Common Grackle (Quiscalus quiscula) nests in which all egg-hatchling dyads were determined unequivocally.

Results: I found that RMA correctly assigned approximately $90 \%$ of hatchlings to their eggs when $2-4$ hatchlings were present between checks. The number of nests in which hatchlings could not be assigned to their egg, however, increased monotonically from 13 to 46 to $78 \%$ for nests containing 2, 3, and 4 hatchlings, respectively, due to the greater likelihood that the mass of hatchlings or their candidate eggs was identical.

Conclusions: Although RMA correctly identified the vast majority of egg-hatchling dyads, researchers should use this method with caution, because it will always inflate positive egg-size effects and thus could potentially result in erroneously reporting significant effects.

Keywords: Egg mass, Hatchling mass, Maternal effects, Hatching synchrony

\section{Background}

Mothers have a variety of ways to manipulate the composition and/or environment of their eggs, including, but not limited to: hatching asynchrony (Clark and Wilson 1981; Magrath 1990), yolk hormones (Groothuis et al. 2005), sex allocation (Pike and Petrie 2003), egg size (Krist 2011), incubation temperature (DuRant et al. 2009, 2011), and carotenoids (Royle et al. 2001; Blount et al. 2002). Assessing how these factors influence the growth and survival of their offspring, however, first requires being able to accurately match hatchlings to their respective eggs. This can be a challenging endeavor for many bird species.

\footnotetext{
*Correspondence: dmaddox@fieldmuseum.org

${ }^{1}$ Pritzker Laboratory for Molecular Systematics and Evolution, Field

Museum of Natural History, Chicago, IL 60605, USA

Full list of author information is available at the end of the article
}

Frequent nest checks can be employed to directly observe the individual hatching of eggs, although increased disturbance at the nest may lead to higher rates of abandonment or predation. Even the most frequent nest checks, however, can result in finding two hatchlings within the same nest. Because egg and hatchling mass are significantly correlated in most bird species (Williams 1994; Deeming and Birchard 2007), simply assigning the heaviest hatchling to the heaviest egg (i.e., relative mass assignment; RMA) in these situations could be tempting, as RMA would increase sample sizes and reduce the number of nest checks required.

Here I present RMA as a new technique, at least to my knowledge, that may be useful in studies of maternal effects, and determine the accuracy of RMA by applying the method retrospectively to a dataset where Common Grackle (Quiscalus quiscula) hatchlings were assigned to eggs unambiguously. Common Grackles 
are an appropriate species in which to test the utility of RMA because hatchling mass is correlated with egg mass (Howe 1976), egg size is variable both within and among clutches (Howe 1976; Maddox and Weatherhead 2008), and 2-4 eggs within a given clutch can hatch at approximately the same time (Howe 1976; Maddox and Weatherhead 2008).

\section{Methods}

I used an incubator with individual compartments to unambiguously assign hatchlings to their respective eggs as part of a larger study investigating maternal effects in Common Grackles. Detailed descriptions of the study site and field methods can be found in Maddox and Weatherhead $(2008,2009,2012)$. Briefly, I found nests under construction and monitored them daily until fledging. On the day each egg was laid, I measured its mass $( \pm 0.1 \mathrm{~g})$ and numbered it sequentially with a nontoxic felt-tip marker. When I observed at least one egg pipping from an individual nest during my daily nest checks, I collected all the eggs from the clutch and placed each egg in an individual compartment within the incubator. In total, eggs from 133 nests were treated as such. Artificial eggs of similar size and appearance were placed in nests to limit female abandonment. Upon hatching I measured the mass $( \pm 0.1 \mathrm{~g})$, wing chord $( \pm 0.1 \mathrm{~mm})$ and tarsus $( \pm 0.1 \mathrm{~mm})$ of each hatchling before returning it to its respective nest.

When more than one egg hatched between checks of the incubator or approximately every $1-2 \mathrm{~h}$, I used RMA to assign hatchlings to their respective eggs by rankordering the mass of hatchlings and their candidate eggs separately and assigning hatchlings to eggs of the same rank (i.e., 1-1, 2-2, etc.). Because I knew the source egg in each case, I could evaluate the error rate of RMA. Typically two eggs from a given clutch hatched between checks but finding 3-4 hatchlings was not uncommon. This is essentially identical to what occurs in the field with frequent nest checks.

\section{Results}

In 78 of the 133 clutches examined, two eggs hatched between consecutive checks of the incubator. RMA correctly matched $122(78.2 \%)$ hatchlings to their respective eggs, whereas 14 (9.0\%) hatchlings were incorrectly assigned. RMA could not be applied to 20 (12.8\%) hatchlings because the mass of the two hatchlings or the two candidate eggs was identical. For those egg-hatchling dyads that were assigned correctly, paired differences of egg and hatchling masses averaged $0.40 \mathrm{~g} \pm 0.03 \mathrm{SE}$ (range $0.1-0.9 \mathrm{~g}, n=61$ ) and $0.38 \mathrm{~g} \pm 0.04 \mathrm{SE}$ (range $0.1-1.4 \mathrm{~g}, n=61)$, respectively. For the 14 egg-hatchling dyads that were assigned incorrectly, paired average differences of egg (0.23 $\mathrm{g} \pm 0.07 \mathrm{SE}$; range 0.1-0.6 g) and hatchling $(0.21 \mathrm{~g} \pm 0.04 \mathrm{SE}$; range $0.1-0.4 \mathrm{~g})$ masses were almost half that of correctly assigned dyads. Excluding those hatchlings that could not be assigned, the error rate of RMA when applied to two hatchlings was $10.3 \%$ $(14 / 136)$.

In 50 of the 133 clutches, three eggs hatched between consecutive incubator checks. RMA correctly matched $66(44 \%)$ hatchlings to their respective eggs, whereas 5 clutches (10\%) had at least one incorrectly assigned hatchling. Twenty-three (46\%) nests contained at least one hatchling that could not be assigned to an egg for the reasons indicated above. Differences in egg mass of correct assignments averaged $0.25 \pm 0.03 \mathrm{SE}$, whereas wrong assignments averaged $0.26 \pm 0.02$ SE. Excluding unassigned hatchlings, the error rate of RMA was $7.0 \%$ (5/71).

In the remaining nine clutches, 4 eggs within the same nest hatched between incubator checks. In one (14\%) clutch, all 4 hatchlings were assigned correctly to their eggs. In another (14\%) clutch, at least one hatchling was incorrectly assigned. In 7 (78\%) clutches, at least one hatchling could not be assigned to an egg for the reasons indicated above. Excluding unassigned hatchlings, the error rate of RMA was $50 \%(1 / 2)$.

\section{Discussion}

RMA was largely successful at correctly assigning hatchlings to their respective eggs. The ability of RMA to assign eggs, however, was highly dependent on the number of hatchlings present between checks. When applied to $\geq 3$ unknown egg-hatchling dyads the percentage of hatchlings that RMA was unable to assign was substantial, essentially eliminating its use in those situations. Consequently, I focus the remaining discussion to those cases where only two hatchlings were found between checks. With only two hatchlings present, RMA may prove to be a useful technique in some species, but its widespread adoption will likely be restricted by several shortcomings.

The accuracy of RMA is likely to vary directly with the extent that egg and hatchling mass are correlated. RMA will almost certainly perform below acceptable levels when egg mass explains little of the variation in hatchling mass. Indeed, those dyads that were incorrectly assigned generally had greater residuals than correctly assigned dyads (Fig. 1). Given that egg mass explained $82 \%$ of the variation in hatchling mass in Common Gracklesa high value for most bird species (Williams 1994) - and yet still incurred a $10 \%$ error rate, RMA should be limited to species in which egg and hatchling mass are highly correlated.

Restricting the application of RMA by a pre-established minimum difference in egg or hatchling mass 


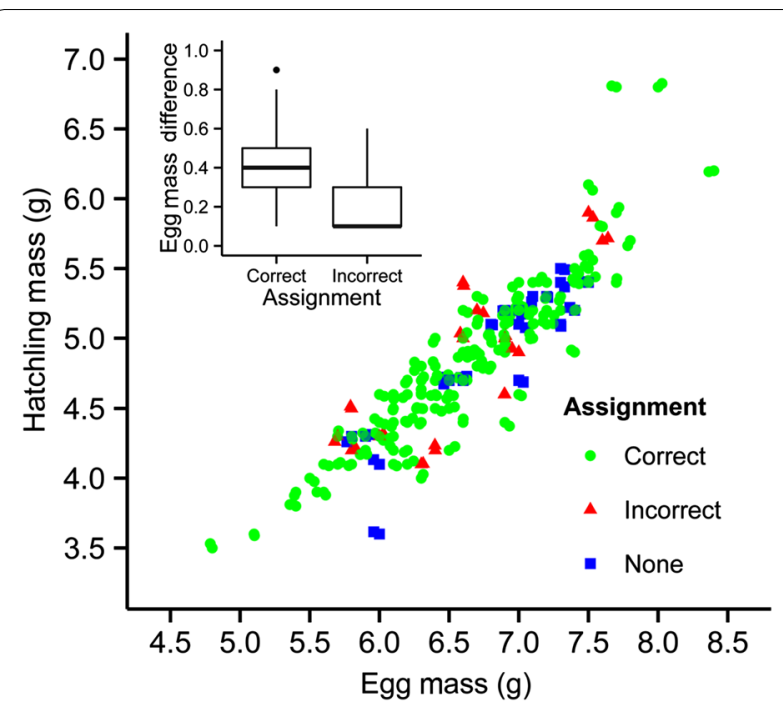

Fig. 1 Relative mass assignment performed better when the difference in egg mass was greater with incorrectly assigned eggs generally having greater residuals than correctly assigned dyads. Colors indicate correct (green), incorrect (red), or unknown (blue) assignments of egg-hatchling dyads

may improve the error rate, because the pair-wise difference in mass was smaller for incorrectly assigned egghatchling dyads than those that were correctly assigned (Fig. 1). Limiting RMA in the current dataset to only eggs that differed in mass by $>0.1 \mathrm{~g}$, reduced the error rate in half to $5 \%$, but doubled the percentage of hatchlings that were unable to be assigned from 13 to $27 \%$. Limiting the assignment of hatchlings had no discernible effect.

A potential pitfall of RMA not accounted for in the present study is the ability of parents to feed hatchlings between nest checks. Given the small difference in mass between nest mates, any amount of food given differentially to hatchlings could alter the mass difference relative to their nest mate and thus potentially result in a wrong assignment. This may prove negligible in many species, especially in species where males provide little parental care, as it is likely that females would still be brooding hatchlings and/or incubating eggs. Common Grackle hatchlings, however, started begging for food immediately after hatching, and I did occasionally observe males feeding hatchlings. Consequently, the error rate I report here is likely a best-case scenario.

One modification to RMA that may improve its accuracy that the current study was unable to assess is to measure egg mass directly before hatching. Given that egg mass decreases during incubation due to water loss as a result of embryonic development (Ar and Rahn 1980), egg mass obtained after this mass loss in addition to or instead of fresh egg mass may decrease the number of incorrect assignments. Future studies will need to verify if this modification would markedly increase the accuracy of RMA.

\section{Conclusions}

RMA may prove to be a valuable tool for studies that require known egg-hatchling dyads, although its accuracy should first be tested on the species in which it will ultimately be applied. Its successful application will likely be limited to those species where egg and hatchling mass are highly correlated or within-clutch egg-size variation is large. Researchers should be cognizant of the fact that RMA is a one-tailed error-egg-size effects will always be inflated-and thus could potentially result in erroneously reporting significant effects when in fact they do not exist.

\section{Author details}

1 Pritzker Laboratory for Molecular Systematics and Evolution, Field Museum of Natural History, Chicago, IL 60605, USA. ${ }^{2}$ Environmental Sciences, American Public University System, Charles Town, WV 25414, USA.

\section{Acknowledgements}

I am indebted to the Shoemaker family for allowing me to work on their land and to the many people who contributed to this project over the years, especially K. Kopatz, C. Johnson, D. Kikuchi, and P. Wesley. Funding was provided by the University of Illinois, Program in Ecology, Evolution and Conservation, and the American Ornithologists' Union Research Award. L.S. Johnson provided useful comments on an earlier version of the manuscript. I was supported by an NSF International Fellowship OISE-1159178 while preparing an earlier version of this manuscript.

\section{Competing interests}

The author declares that he has no competing interests.

\section{Ethical standards}

All work described here was approved by the Institutional Animal Care and Use Committee (IACUC) at the University of Illinois (protocol \#05006).

Received: 20 February 2017 Accepted: 27 June 2017

Published online: 01 July 2017

\section{References}

Ar A, Rahn H. Water in the avian egg overall budget of incubation. Am Zool. 1980;20:373-84.

Blount JD, Surai PF, Nager RG, Houston DC, Møller AP, Trewby ML, Kennedy MW. Carotenoids and egg quality in the lesser black-backed gull Larus fuscus: a supplemental feeding study of maternal effects. Proc R Soc B Biol Sci. 2002;269:29-36.

Clark A, Wilson D. Avian breeding adaptations: hatching asynchrony, brood reduction, and nest failure. Q Rev Biol. 1981;56:253-77.

Deeming DC, Birchard GF. Allometry of egg and hatchling mass in birds and reptiles: roles of developmental maturity, eggshell structure and phylogeny. J Zool. 2007;271:78-87.

DuRant SE, Hepp GR, Moore IT, Hopkins BC, Hopkins WA. Slight differences in incubation temperature affect early growth and stress endocrinology of wood duck (Aix sponsa) ducklings. J Exp Biol. 2009;213:45-51.

DuRant SE, Hopkins WA, Wilson AF, Hepp GR. Incubation temperature affects the metabolic cost of thermoregulation in a young precocial bird. Funct Ecol. 2011;26:416-22.

Groothuis TGG, Muller W, Von Engelhardt N, Carere C, Eising C. Maternal hormones as a tool to adjust offspring phenotype in avian species. Neurosci Biobehav Rev. 2005;29:329-52. 
Howe HF. Egg size, hatching asynchrony, sex, and brood reduction in the common grackle. Ecology. 1976;57:1195-207.

Krist M. Egg size and offspring quality: a meta-analysis in birds. Biol Rev. 2011;86:692-716.

Maddox JD, Weatherhead PJ. Egg size variation in birds with asynchronous hatching: is bigger really better? Am Nat. 2008;171:358-65.

Maddox JD, Weatherhead PJ. Seasonal sex allocation by Common Grackles? Revisiting a foundational study. Ecology. 2009;90:3190-6.

Maddox JD, Weatherhead PJ. Discrepancy between factors affecting nestling growth and survival and maternal success in Common Grackles. J Field Ornithol. 2012;83:17-25.
Magrath RD. Hatching asynchrony in altricial birds. Biol Rev. 1990;65:587-622. Pike T, Petrie M. Potential mechanisms of avian sex manipulation. Biol Rev. 2003;78:553-74.

Royle NJ, Surai PF, Hartley IR. Maternally derived androgens and antioxidants in bird eggs: complementary but opposing effects? Behav Ecol. 2001;12:381-5.

Williams TD. Intraspecific variation in egg size and egg composition in birds: effects on offspring fitness. Biol Rev. 1994;68:35-59.

\section{Submit your next manuscript to BioMed Central and we will help you at every step:}

- We accept pre-submission inquiries

- Our selector tool helps you to find the most relevant journal

- We provide round the clock customer support

- Convenient online submission

- Thorough peer review

- Inclusion in PubMed and all major indexing services

- Maximum visibility for your research

Submit your manuscript at

www.biomedcentral com/submit 